\title{
Physical activity is associated with low-level stress among a sample of seniors during COVID-19 outbreak?
}

\author{
Atividade física está associada com baixos níveis de estresse em uma amostra de \\ idosos durante a pandemia de COVID-19?
}

\section{AUTHOR'S \\ Chellsea Hortêncio Alcântara ${ }^{1,2}$ (D) \\ Rafael Martins da Costa ${ }^{3}$ (i) \\ Elorides de Brito $^{1}$ (D) \\ Maira Mendes dos Santos Marques ${ }^{1}$ (D) \\ Euler Esteves Ribeiro ${ }^{1}$ (1D \\ Elisa Brosina de Leon ${ }^{1,2,4}$ (iD \\ 1 Fundação Universidade Aberta da Terceira Idade, Manaus, Amazonas, Brazil. \\ 2 Universidade Federal do Amazonas, Faculdade de Educação Física e Fisioterapia, Manaus, Amazonas, \\ Brazil. \\ 3 Universidade Federal de Santa Catarina, \\ Programa de Pós-Graduação em Educação Física, \\ Santa Catarina, Brazil. \\ 4 Programa de Pós Graduação Stricto Sensu em \\ Ciências do Movimento Humano, Faculdade \\ de Educação Física e Fisioterapia, Universidade \\ Federal do Amazonas, Manaus, Amazonas, Brazil.}

\section{CORRESPONDING}

\section{Elisa Brosina de Leon}

elisadleon@ufam.edu.br

Universidade Federal do Amazonas/ Facul-

dade de Educação Física e Fisioterapia

Av. General Rodrigo Octávio, 6200 - Coroado I, Manaus, Amazonas, Brazil.

ZIP CODE: 69080-900.

\section{DOI}

$10.12820 /$ rbafs.26e0226

\section{(cc) BY}

This work is licensed under a Creative Commons Attribution 4.0 International License.

\begin{abstract}
This study aimed to verify the association of physical activity, behaviors, and health conditions with stress among a sample of older adults from Manaus, Brazil, during the COVID-19 outbreak. This is a cross-sectional analysis of 79 older adults (76\% female; age: $68.24 \pm 6.82$ years) from Fundação Universidade Aberta da Terceira Idade (FUnATI). The perceived stress (PS) was assessed by the Perceived Stress Scale, while a questionnaire via telephone call. The variables also included physical activity, sleep quality, sociodemographic, and health condition variables. Linear Bayesian mixed-effects regression models were applied to verify the association between these correlates with PS. Older people who met the recommendations before the COVID-19 outbreak but did not meet the same recommendations during the COVID-19 outbreak have a higher PS score compared to those older people who did not meet the PA recommendations at either time. In contrast, those elderly people who met PA recommendations before and during the COVID-19 outbreak had a lower PS score compared to their peers who did not meet physical activity recommendations at either time. Those older people who did not meet the PA recommendations before the COVID-19 outbreak, but did meet the PA recommendations during the COVID-19 outbreak, did not have significant differences in the PS score compared to their peers who did not meet the PA recommendations in either moment. Sleep changes and high BMI were negatively associated with PS. The maintenance of physical activity during the pandemic was associated with lower levels of stress in older people.
\end{abstract}

Keywords: Aged; Psychological stress; Physical exercise; Pandemics; Sleep.

RESUMO

Este estudo teve como objetivo verificar a associação de atividade física, comportamentos e condiçôes de saúde associadas ao estresse em uma mostra de idosos de Manaus, Brasil, durante o surto COVID-19. Trata-se de uma análise transversal ( $n=79$ idosos; $76 \%$ mulheres; idade: $68,24 \pm 6,82$ anos) da Fundação Universidade Aberta da Terceira Idade (FUnATI). O estresse percebido (EP) foi avaliado utilizando a Escala de Estresse Percebido, aplicado via ligação telefônica. O questionário também incluiu atividade física, qualidade do sono, variáveis sociodemográficas e de condição de saúde. Modelos de regressão linear Bayesiana de efeitos mistos foram aplicados para verificar a associação entre esses correlatos com EP. Idosos que atendiam às recomendações de AF antes do surto de COVID-19 mas não mantiveram a prática durante o surto apresentaram pontuação de EP mais alta em comparação com os idosos que não atendiam às recomendaçôes em nenhum dos momentos. Em contraste, os idosos que mantiveram os niveis de AF tiveram uma pontuação de EP mais baixa. Idosos que não atenderam às recomendaçôes de AF antes do surto de COVID-19, mas atenderam às recomendaçôes de $P A$ durante o surto de COVID-19 não tiveram diferenças significativas na pontuação de EP. Mudanças no sono e alto IMC foram associados negativamente com o EP. A manutenção da atividade física durante a pandemia foi associada a niveis mais baixos de estresse em pessoas mais velhas.

Palavras-chave: Idosos; Estresse psicológico; Exercício físico; Pandemias; Sono.

\section{Introduction}

More than one year has passed since the first cases of pneumonia caused by a new viral agent called severe acute respiratory coronavirus 2 (SARS-CoV-2) were reported in Wuhan, China ${ }^{1}$. The rapid increase in the number of contagions ${ }^{2}$ and the relentless international spread of the virus has led the World Health Organization (WHO) to declare the so-called 2019 Coronavirus Disease (COVID-19) a global pandemic on March $2020^{3}$. Consequently, government entities in different countries adopted abrupt and drastic population isolation measures to prevent the increase in the number of 
contagions. At this time, in Amazonas's State, northern Brazil, the first state decree ( $n^{\circ}$ 42061) came out on March 16, 2020 declaring an emergency and suspension of in person activities with the aim of preventing the transmission of the COVID-19. On March 27, 2020, the first official bulletin of the Health Surveillance Foundation (FVS) was released (80 confirmed cases in the state of Amazonas). Furthermore, until May 31, 2020 (two days before the beginning of the data collection of this study) Brazil confirmed through the Ministry of Health, 514.849 cases and 29.314 deaths, which represented a lethality of $5.7 \%$. In the same period, Amazonas had the second highest incidence rate among Brazilian states, with 979 cases per 100 thousand inhabitants, 4 times higher than the national average, of 245 cases per 100 thousand inhabitants; in addition, it was the state with the highest mortality (49 deaths/100 thousand inhabitants).

Previous researches focused on the COVID-19 outbreak period has identified negative consequences of social isolation for mental health in the general population ${ }^{4}$. During this unprecedented outbreak, the entire population has been forced to suffer a physical risk and impaired emotional well-being, but older adults have undoubtedly been one of the most vulnerable groups ${ }^{5}$. In addition, the social consequences of quarantine must also be considered. Social disconnection is especially important for this age group less used to digital technologies as it may limit social engagement, interfere with daily routines, enhance inactivity, increase drug use, and decrease sensory stimulation ${ }^{5}$. All these circumstances together with social distancing might have an adverse impact on the mental health of the older adults' population. Besides, the high stress in the elderly population can also be caused by a risk of developing serious diseases during the pandemic, and by the fear of death from COVID-19 $9^{6,7}$.

Stress is a defensive reaction against threatening environmental conditions, which is associated with activation of the sympathetic nervous system and responses from other body systems ${ }^{8}$. Perceived stress (SP) is experienced as a negative feeling and is associated with adverse health consequences, including increased cardiovascular risks, hypertension, risk of metabolic syndrome, cancer, social adversity, and insomnia ${ }^{9}$. The Perceived Stress Scale has been used to measure physiological stress and has been shown to be associated with high markers of biological aging, higher cortisol levels, suppressed immune function, greater suscepti- bility to infectious diseases ${ }^{10}$. It was also observed that there is an increase in the perception of stress related to increasing age ${ }^{11}$. In addition, the elderly present highly prevalent sedentary behavior, changes in sleep quality, greater risk of vulnerability, presence of pain, and multimorbidity ${ }^{11,12}$. In contrast, physical activity (PA) was associated with lower PS in observational studies ${ }^{13}$.

Further, COVID-19 can act as a stressor, creating collective panic due to the distance from uncertainty and lack of knowledge ${ }^{4}$. Furthermore, its rapid transmission rate, infectious nature, and serious life-threatening can contribute to increased levels of anxiety. This state of emergency in response to COVID-19 is likely to make the anxiety-prone population experience high levels of stress ${ }^{14}$. On the other hand, studies on the subject in previous pandemics show that older people are less likely to have high levels of stress and are more apt to manage their stresses during pandemics when compared to young adults ${ }^{15,16}$. Thus, data on perceived stress and its correlates during the COVID-19 outbreak remain conflicting and inconclusive, and further studies are needed to investigate such hypotheses.

Therefore, this study aimed to verify the association of PA, behavioral and health conditions correlated with PS in a sample of elderly people from Manaus, Brazil, during the COVID-19 outbreak. Given the current scenario and the deleterious effects on mental health, specifically on stress, among the elderly during the social distancing caused by COVID-19, the hypothesis was that carrying out PA during the pandemic would help to reduce the perception of stress. In addition, trained elderly people who underwent PA before the pandemic would remain active and have a lower perception of stress.

\section{Methods}

This study used a cross-sectional design with a convenience sample and was conducted in the Policlinica Gerontológica da Fundação Universidade Aberta da Terceira Idade (FUnATI). FUnATI is an institution designed to serve older people which offers free courses, workshops, and health service called Policlínica Gerontológica da FUnATI. Participants were recruited from a study called Development and Evaluation of Care Strategies for Old People at Risk of Frailty developed at Policlínica Gerontológica and met the following inclusion criteria: 1 ) be aged $\geq 60 ; 2$ ) classified as robust or at risk of frail according to Clinical Functional Vulnerability Index-20 (IVCF-20) ${ }^{17}$. Volunteers with 
communication difficulties who were unable to understand the questions were excluded from the study.

In June 2020, a questionnaire was utilized by phone in all participants $(\mathrm{n}=79)$ aiming to evaluate the PS, behavioral, and other health condition variables of the participants. The questionnaire also included questions on sociodemographic conditions (assessment of sociodemographic and health condition variables). The participation was voluntary, and participants could withdraw at any time without any penalty. All participants signed an informed consent form. This study was approved by the Research Ethics Committee of the local university (80460917.6.0000.5016).

The Clinical- Functional Vulnerability Index-20 (IVCF-20) instrument was used for screening frailty in older adults. The IVCF-20 is a questionnaire that covers multidimensional aspects of the older adult's health condition and has 20 questions divided into eight sections: age (one question), health self-perception (one question), functional disabilities (four questions), cognition (three questions), mood (two questions), mobility (six questions), communication (two questions) and multiple comorbidities (one question). Each section has a specific score that compose a maximum amount of 40 points. The higher the value obtained represent higher risk of clinical-functional vulnerability of the older adults which classify into robust older adults or older at risk of frail or frail older adults ${ }^{17}$.

The PS scale (PSS) is a general scale used to measure perceived stress ${ }^{20}$ which can be used in different age groups and different cultures because does not contain context specific issues of a determined culture. The PSS consists of 14 questions ranging from zero to four $(0=$ never $; 1=$ almost never $; 2=$ sometimes $; 3=$ almost always and $4=$ always) that account for a sum between 0 to 56 . Higher score represents higher perceived stress.

The International Physical Activity Questionnaire (IPAQ) was used to estimate the weekly time spent in moderate and vigorous $\mathrm{PA}$ and sitting time. The short form of IPAQ was adopted to not extend phone call duration. The changes in routine due to social distancing and duration of calls were crucial for this choice. The moderate to vigorous PA was measured before (active before) and during outbreak (active during), following to World Health Organization recommendations ( $150 \mathrm{~min} /$ week in moderate to vigorous $\mathrm{PA}^{19}$ ).

Participants were asked about presence of pain (have you been feeling any pain in the last days?), sleep quality: sleeping difficulties (have you been having trouble sleeping for the past few days? response options were: frequently, sometime or none) and wake up frequency during sleeping ("recently, have you frequently woken up during your sleep period?". response options were: yes or no).

All sociodemographic variables as sex, age, financial incomes, and body mass index (BMI) were collected by a nurse between November 2019 and February 2020. Personal financial income was measured by the following question: "Is your income sufficient for your basic needs?" (answers: yes/no). Body mass $(\mathrm{kg})$ and height $(\mathrm{cm})$ were measured in a private room. The body mass was measured once using a balance calibrated to the nearest $0.1 \mathrm{~kg}\left(\right.$ Ramuza $\left.^{\circledR}\right)$, and a stadiometer (Ramu$\left.\mathrm{za}^{\circledR}\right)$ was used to measure stature to the nearest $0.1 \mathrm{~cm}$.

Characteristics of the sample are presented using means and standard deviation for continuous data, minimum and maximum values, and absolute and relative frequencies for categorical data. Linear Bayesian mixed-effects regression models were used to verify the association of each variable and hierarchical entry models, with consideration given to the multilevel structure of the data, where older adults are nested within the age categories. Mixed-effect models allow certain variables to vary randomly within an established condition. The Bayesian approach allows the researcher to enter prior information (mean: 22.0, standard-deviation: 8.0) from his belief or previous studies and then estimate the posterior distribution and update their knowledge and prior information about the outcome. Furthermore, Bayesian approaches to data analysis can be a good alternative to traditional hypothesis testing. Unlike $\mathrm{P}$ values, Bayesian analyses can provide a direct measure of the strength of evidence both for and against a study hypothesis, which can be helpful for researchers to interpret and make decisions about their results.

Four models were tested. Model 1 is composed only by behavioral variables (moderate to vigorous PA before and during the COVID-19 outbreak, sitting time, and interaction term between moderate to vigorous $\mathrm{PA}$ before and during the COVID-19 outbreak); model 2 is composed only by health condition variables (vulnerability, presence of pain, frequent awakening, difficulty sleeping, BMI, and the sum of comorbidities); model 3 is the full model composed of all variables; model 4 is composed only of the variables associated with the PSS after the stepwise procedure. For the Bayesian parameters we used informative prior distributions for the intercept in the population-level with normal distribution priors, that is, to ensure that the results reflect the 
knowledge supplied by the current data and allow for model convergence. We then implemented the Markov Chain Monte Carlo simulation and using the Hamiltonian Monte Carlo and its extension, the No-U-Turn Sampler using Stan, with four chains for 2000 iterations and warm-up length of 800 iterations. Finally, we used the Leave-One-Out Cross-Validation (LOO-CV) and Widely Applicable Information Criteria (WAIC) procedures to compare the models and verify which was the best (the lower the values, the better the model) and the posterior predictive checks to verify the posterior distribution of the data. The information about the association models is presented in coefficients and 90\% credible intervals. We tested the interaction between meeting the PA recommendations (before/during the COVID-19 outbreak) and sitting time, sleep quality indicators, vulnerability, sum of comorbidities, $\mathrm{BMI}$, and sociodemographic factors, but no substantial differences were found in the models. Only an interaction between meeting the PA recommendations before and during de COVID-19 outbreak was relevant found and inserted in the models. All models were adjusted for the sociodemographic factors. Linear Bayesian mixed-effects regression models were performed using the "brms" package version 2.13 .5 of R statistical software version 4.0.1 via Stan programming language. Information about the graphs of the residual analysis, trace plots, and posterior predict checks of the model 4, are presented in Supplementary Material.

\section{Results}

Initially, 96 elderly people met the inclusion criteria and were invited to participate in the study. Of these, 80 agreed to participate in the study and only one participant did not complete the telephone interview. Thus, the final sample consisted of 79 elderly people. Most of the sample consisted of women, mean age of 68.24 ( \pm 6.82) years, with sufficient financial income, classified as robust vulnerability, without pain presence, did not have difficulty sleeping, slightly do not wake up frequently, and presented two comorbidities for the sum of comorbidities (Table 1). Data showed that $76 \%$ participants practiced less than 150 minutes of moderate to vigorous PA before the COVID-19 outbreak, and 83\% started practicing PA during the COVID-19 outbreak (Table 1). The older adults in this study had a low level of stress, a BMI considered to be overweight (Table 1).

In the set of behavioral variables, moderate to vigorous PA before the COVID-19 outbreak and the inter-
Table 1 - Cross-sectional descriptive analysis of older adults from Manaus, Amazonas, Brazil, 2020 ( $\mathrm{n}=79)$

\begin{tabular}{ll}
\hline Variables & $\mathrm{n}(\%)$ \\
\hline Sex & $60(76.0)$ \\
Female & $19(24.0)$ \\
Male & \\
Age group & $53(67.1)$ \\
$60-69$ & $17(21.5)$ \\
$70-79$ & $9(11.4)$ \\
$80-89$ & \\
Sufficient financial income & $44(55.7)$ \\
Yes & $35(44.3)$ \\
No & \\
Vulnerability & $26(32.9)$ \\
At risk of frailty & $53(67.1)$ \\
Robust
\end{tabular}

Sum of comorbidities

$120(25.3)$

$223(29.1)$

3 12 (15.2)

$4 \quad 14(17.7)$

Presence of pain

Yes $16(20.3)$

$\begin{array}{ll}\text { No } & 63(79.7)\end{array}$

Frequent awakening

$\begin{array}{ll}\text { Yes } & 38(48.1)\end{array}$

No $\quad 41(51.9)$

Difficulty sleeping

Frequently $\quad 8(10.1)$

Sometimes $20(25.3)$

Doesn't happen to me 51 (64.6)

Moderate to vigorous physical activity before the COVID-19 outbreak

$\geq 150 \mathrm{~min} / \mathrm{week} \quad 19(24.0)$

$<150 \mathrm{~min} /$ week $\quad 60(76.0)$

Moderate to vigorous physical activity during the COVID-19 outbreak

$\geq 150 \mathrm{~min} /$ week $\quad 66$ (83.5)

$<150 \mathrm{~min} /$ week $13(16.5)$

\begin{tabular}{lcc}
\hline & $\begin{array}{c}\text { Mean (standard } \\
\text { deviation) }\end{array}$ & $\begin{array}{c}\text { Minimum and } \\
\text { maximum values }\end{array}$ \\
\hline Perceived Stress Scale $(0-56)$ & $10.72(7.09)$ & $0.00 ; 36.00$ \\
Body mass index $\left(\mathrm{kg} / \mathrm{m}^{2}\right)$ & $29.05(5.07)$ & $17.10 ; 53.50$ \\
Sitting time (hours/day) & $3.82(1.70)$ & $1.00 ; 11.00$ \\
\hline
\end{tabular}

action term PA before - during COVID-19 outbreak 
were associated with PS in models 1 (only behavioral variables), 3 (full model; all variables), and 4 (only variables associated with PS after the stepwise procedure). The association of the interaction term indicates that those older people who met the recommendations before the COVID-19 outbreak but did not meet the same recommendations during the COVID-19 outbreak had a higher PS score compared to those older people who did not meet the PA recommendations at either time. In contrast, those elderly people who met $\mathrm{PA}$ recommendations before and during the COVID-19 outbreak had a lower PS score compared to their peers who did not meet PA recommendations at either time. Those older people who did not meet the PA recommendations before the COVID-19 outbreak, but did meet the PA recommendations during the COVID-19 outbreak, did not have significant differences in the PS score compared to their peers who did not meet the PA recommendations in either moment (Table 2). About the health condition variables, only frequent awakening was associated in the crude model, models 2 (only health condition variables), 3 , and 4 (Table 2).

LOO-CV and WAIC showed decreases in their values as the models were tested, except for an increase from model 2 to model 3 followed by a further decrease from model 3 to model 4 (Table 2). Model 5 was the model with the lowest LOO-CV and WAIC values when compared to previous models; indicating that this is the best model tested. Based on these results, we adopted model 5 to proceed with the study's discussion.

\section{Discussion}

In this study, we aimed to verify the associations of PA, behavioral, and health conditions correlates with the PS in a sample of older adults from Manaus, Brazil, during the COVID-19 outbreak. Of all the correlates tested, data showed that those who kept meeting the PA recommendations during outbreak showed less PS, compared to those who never met the PA recommendations. On the other hand, elderly people who met PA recommendations before the outbreak but did not meet PA recommendations during the outbreak showed more PS, compared to those who never met the PA recommendations. While those who reported frequently awakening and BMI $z$-score presented positively associated with the PS.

Most of the population recognize the benefits of $\mathrm{PA}$, including improvement in sleep quality, weight control and relieve stress but report the financial access as a barrier to practice ${ }^{18}$. Many people across the world are socially vulnerable and they are focused on meeting their essential basic needs first to consider engaging in PA during the outbreak ${ }^{19}$. We found that older adults who practiced more than 150 minutes of moderate to vigorous PA before and during the COVID-19 outbreak presented the lowest scores of PS in this sample. The exercise intensity may influence the PS and exercising at home may allow a deep feeling of satisfaction and can help with psychological well-being benefits $^{19,20}$. Moreover, time in PA can reduce cortisol responses regardless of the PA level. Thus, the interruption of PA practices during a stressful period can contribute to high levels of PS. This finding suggests that maintaining a more active lifestyle even in quarantine is important to present less perceived stress. However, studies with a longitudinal design are need to confirm this hypothesis.

It is noteworthy that meeting the PA recommendations before the pandemic was not enough to prevent high stress in this sample of older adults during the COVID-19 outbreak. Several physiological and psychological explanations for a possible dampening effect of regular PA on stress have been suggested ${ }^{22}$. One of them is the cross-stressor-adaptation (CSA) hypothesis. According to the CSA hypothesis, exposure to physical stress (e.g., MVPA) triggers a stress response comparable to that found in response to psychosocial stressors ${ }^{22}$. The basic assumption behind the CSA hypothesis is that the beneficial adaptation of the activity of the hypothalamic-pituitary-adrenocortical (HPA) axis and the medullary sympathoadrenal (SM) system during the physical stress of regular PA may generalize to other non-physical stressors (e.g., cognitive stressors) ${ }^{22}$. Thus, the elderly who only met the PA recommendations before the COVID-19 outbreak did not have the necessary physical stimuli during the pandemic, which did not lead to higher caloric expenditure and, consequently, there was no beneficial adaptation of the activities of the HPA axis and the SM system and mitigating the effects of cognitive stressors. However, the cross-sectional design and measures used in this study do not allow us to confirm these hypotheses.

The data showed lower stress levels in the studied population despite this group being considered at greater risk, yet they have better mental health than younger adults $^{23}$. Other studies have reported that older adults over 60 years are less vulnerable than younger adults 
Table 2 - Association of behavioral and health condition variables with perceived stress scale among older adults ( $\mathrm{n}=79)$, Manaus, Amazonas, Brazil, 2020.

\begin{tabular}{|c|c|c|c|c|c|}
\hline & Crude & Model 1 & Model 2 & Model 3 & Model 4 \\
\hline & $\beta(90 \% \mathrm{CI})$ & $\beta(90 \% \mathrm{CI})$ & $\beta(90 \% \mathrm{CI})$ & $\beta(90 \% \mathrm{CI})$ & $\beta(90 \% \mathrm{CI})$ \\
\hline & $\begin{array}{l}\text { Perceived Stress } \\
\text { Scale }\end{array}$ & $\begin{array}{l}\text { Perceived Stress } \\
\text { Scale }\end{array}$ & $\begin{array}{l}\text { Perceived Stress } \\
\text { Scale }\end{array}$ & $\begin{array}{l}\text { Perceived Stress } \\
\text { Scale }\end{array}$ & $\begin{array}{l}\text { Perceived Stress } \\
\text { Scale }\end{array}$ \\
\hline \multicolumn{6}{|l|}{ Population-levels effects } \\
\hline Intercept & - & $12.47(7.34 ; 17.75)$ & $7.48(1.11 ; 14.75)$ & $6.10(-0.73 ; 13.79)$ & $7.97(2.56 ; 14.49)$ \\
\hline \multicolumn{6}{|l|}{ Behavioral variables } \\
\hline \multicolumn{6}{|c|}{$\begin{array}{l}\text { Moderate to vigorous physical activity before } \\
\text { the COVID- } 19 \text { outbreak }\end{array}$} \\
\hline$<150 \mathrm{~min} /$ week & Ref. & Ref. & - & Ref. & Ref. \\
\hline$\geq 150 \mathrm{~min} /$ week & $0.88(-2.39 ; 4.13)$ & $13.60(4.69 ; 23.14)$ & & $10.10(1.99 ; 18.23)$ & $9.73(1.57 ; 17.97)$ \\
\hline \multicolumn{6}{|l|}{$\begin{array}{l}\text { Moderate to vigorous physical activity } \\
\text { during the COVID-19 outbreak }\end{array}$} \\
\hline$<150 \mathrm{~min} /$ week & Ref. & Ref. & - & Ref. & Ref. \\
\hline$\geq 150 \mathrm{~min} /$ week & $-4.12(-7.95 ;-0.38)$ & $-1.36(-5.62 ; 2.80)$ & & $1.91(-2.48 ; 6.14)$ & $0.13(-3.72 ; 3.96)$ \\
\hline $\begin{array}{l}\text { Moderate to vigorous physical activity } \\
\text { Before - During }\end{array}$ & - & $\begin{array}{l}-13.87(-23.55 \\
-4.26)\end{array}$ & - & $\begin{array}{l}-10.12(-18.85 \\
-1.59)\end{array}$ & $\begin{array}{l}-10.17(-18.70 \\
-1.59)\end{array}$ \\
\hline Sitting time & $-0.03(-0.84 ; 0.79)$ & $-0.05(-0.89 ; 0.80)$ & - & $-0.17(-1.06 ; 0.71)$ & - \\
\hline \multicolumn{6}{|c|}{ Health condition variables } \\
\hline \multicolumn{6}{|l|}{ Vulnerability } \\
\hline At risk of frailty & Ref. & - & Ref. & Ref. & - \\
\hline Robust & $1.57(-1.37 ; 4.54)$ & & $-1.14(-3.94 ; 1.73)$ & $-0.73(-3.73 ; 2.23)$ & \\
\hline \multicolumn{6}{|l|}{ Presence of pain } \\
\hline No & Ref. & - & Ref. & Ref. & - \\
\hline Yes & $4.08(0.62 ; 7.47)$ & & $2.07(-1.21 ; 5.29)$ & $2.07(-1.47 ; 5.53)$ & \\
\hline \multicolumn{6}{|l|}{ Frequent awakening } \\
\hline No & Ref. & - & Ref. & Ref. & Ref. \\
\hline Yes & $7.92(5.53 ; 10.27)$ & & $7.56(5.00 ; 10.17)$ & $6.95(4.14 ; 9.70)$ & $7.47(5.03 ; 9.91)$ \\
\hline \multicolumn{6}{|l|}{ Difficulty sleeping } \\
\hline Doesn't happen to me & Ref. & - & Ref. & Ref. & - \\
\hline Sometimes & $4.52(1.45 ; 7.56)$ & & $0.99(-2.07 ; 4.03)$ & $0.80(-2.29 ; 3.87)$ & \\
\hline Frequently & $4.72(0.42 ; 9.06)$ & & $1.05(-3.14 ; 5.33)$ & $0.97(-3.28 ; 5.28)$ & \\
\hline BMI z-score & $1.08(-0.29 ; 2.44)$ & - & $0.99(-0.16 ; 2.14)$ & $0.88(-0.27 ; 2.08)$ & $1.22(0.04 ; 2.38)$ \\
\hline \multicolumn{6}{|l|}{ Sum of comorbidities } \\
\hline 0 & Ref. & - & Ref. & Ref. & - \\
\hline 1 & $0.95(-3.77 ; 5.78)$ & & $0.77(-3.60 ; 5.12)$ & $0.85(-3.72 ; 5.52)$ & \\
\hline 2 & $-3.05(-7.68 ; 1.60)$ & & $-0.84(-5.05 ; 3.49)$ & $-0.97(-5.48 ; 3.54)$ & \\
\hline 3 & $3.26(-2.02 ; 8.63)$ & & $3.82(-1.08 ; 8.74)$ & $4.20(-1.20 ; 9.57)$ & \\
\hline 4 & $1.99(-3.18 ; 7.27)$ & & $2.78(-2.01 ; 7.66)$ & $2.25(-2.75 ; 7.26)$ & \\
\hline Group-level effects & $\begin{array}{l}\text { Standard deviation } \\
(90 \% \mathrm{CI})\end{array}$ & $\begin{array}{l}\text { Standard deviation } \\
(90 \% \mathrm{CI})\end{array}$ & $\begin{array}{l}\text { Standard deviation } \\
(90 \% \mathrm{CI})\end{array}$ & $\begin{array}{c}\text { Standard deviation } \\
(90 \% \mathrm{CI})\end{array}$ & $\begin{array}{l}\text { Standard deviation } \\
\quad(90 \% \mathrm{CI})\end{array}$ \\
\hline Age group & - & $2.22(0.15 ; 6.55)$ & $5.20(1.21 ; 11.79)$ & $4.33(0.58 ; 10.62)$ & $4.09(0.43 ; 10.10)$ \\
\hline LOO-CV & - & 537.5 & 519.1 & 530.5 & 517.3 \\
\hline WAIC & - & 536.0 & 517.6 & 525.7 & 514.8 \\
\hline
\end{tabular}

Note - Credible interval values that do not intersect, i.e., both negative or positive values represent relevant associations. $\beta=$ coefficient; $\mathrm{CI}=$ credible interval; Ref. = reference category; MVPA = moderate to vigorous physical activity = BMI: body mass index; LOO-CV = Leave-OneOut Cross Validation; WAIC = Widely Applicable Information Criteria. Model 1 - Only behavioral variables; Model 2 - Only health condition variables; Model 3 - Full model (behavioral and health condition variables); Model 4 - Only variables associated with the perceived stress scale.

about concerns to the pandemic and suffering from depression and stress during the outbreak ${ }^{5,23}$. Studies pri- or to the COVID-19 outbreak already reported lower stress scores in the elderly compared to younger age 
groups ${ }^{15,16}$. In fact, older adults are more likely to use attentional, appraisal, and behavioral strategies to minimize stressful situations and should therefore show more favorable stress responses compared with young adults ${ }^{15}$. The sustained challenges caused by the outbreak put into question whether age-related advantages in mental health will persist during this crisis ${ }^{23}$.

Also, the fact that the sample studied was composed of elderly people who are robust or at moderate risk of frailty, including elderly individuals without functional dependency and capable of managing their lives in an independent and autonomous manner could have interfered with the results. Frail older adults present highest prevalence of complete dependency in instrumental activities of daily living, as well as greater presence of pain $^{17}$. This criterion may have been one of the reasons for low-stress levels and no association of vulnerability and the presence of pain with PS in this sample. Although our findings revealed that older adults had low-stress levels during the COVID-19 outbreak, their physical health should continue to be a major public health priority. Efforts to bolster mental health during COVID-19 could focus on modifying stress appraisals, promoting physically distanced daily positive events ${ }^{23}$.

In the older adults of this study, frequent awakening was negatively associated with the PS during the COVID-19 outbreak. In the aging process some alterations in sleep architecture, quality, and quantity are considered normal (tend to become shorter, more shallow and more disrupted $)^{24}$. Despite the poor sleep quality being a common complaint in this population, the older adults investigated did not present difficulty sleeping but rather to maintain sleep, and this has been suggested as a psychological response to stressful events ${ }^{12}$.

The number of comorbidities of the sample did not associate with PS. In a review about the subject, the presence of multimorbidity increases in very old persons, women and people from lower social classes ${ }^{25}$. Despite the study population being mostly women, the age was not so advanced and the participants had sufficient income for basic needs. Another point that may have influenced the non-association of number of $\mathrm{co}^{-}$ morbidities and PS is the severity of the comorbidities, that was not investigated in this study. Individuals with severe multimorbidity presented higher $\mathrm{PS}^{26}$.

Despite the similarities in relation to sleep, it is important to highlight that, in this study, sex was not associated with PS, but there was a positive associa- tion with BMI, corroborant with other studies ${ }^{27,28}$. The $\mathrm{BMI}$ has been associated with high levels of $\mathrm{cortisol}^{27}$, which may be due to the role of visceral adipose tissue inflammation ${ }^{29}$ and then may precede changes in stress reactivity or stress recovery ${ }^{30}$. This shows that it is important is important to adopt and/or maintain a healthy lifestyle aiming to reduce or maintain the BMI of the older adults, mainly at the period of the COVID-19 outbreak.

The present study had some strengths. The participants of this research are from the population most affected by the COVID-19, from the findings we can better understand how the elderly faced quarantine. The state of Amazonas is one of the most affected by the outbreak in Brazil and the data collection period was carried out during the most troubled period of the outbreak. Another strength of the study was sophisticated and robust statistical analyses performed to verify which variables are associated with PSS. Some limitations were also notable, firstly the use of a questionnaire which implies memory bias and social desirability. Secondly, in order to minimize the time of the telephone interview, we chose to use the short version of the IPAQ, but this version has not been validated for the Brazilian elderly population. This can lead to psychometric weaknesses such as lower accuracy in the values obtained by this telephone questionnaire. Thirdly, the sample was non-probabilistic and possibly present selection bias, since the older adults of this sample already were involved in health promotion activities, thus not being representative of the older adults from Manaus, Brazil. Fourthly, our study did not take into account use of medications that may influence cortisol concentration (e.g., steroids or hormone replacement therapies).

Due to the cross-sectional design, causality cannot be assumed but health professionals who care for the elderly should pay attention to the promotion of physical activities, a better quality of sleep, and decrease or maintenance of the body mass index, aiming at reducing the perceived stress in the elderly population. Furthermore, future studies should include other measures of psychological concepts beyond the stress (i.e., ego-integrity, self-efficacy, and resilience) and physiological indicators (e.g., cortisol), and combine objective (e.g., accelerometers for measuring physical activity at different intensities, sedentary behavior, and sleep hygiene, efficiency, and latency) and self-reported (e.g., types and domains of PA, time spent on different screen and non-screen activities) measures to inves- 
tigate their relationship with PSS, using longitudinal designs. In addition, we recommend that future studies aim to create/validate cutoff points for the PSS-14 in order to support messages about stress and public health in the elderly population.

In sum, the lowest perception of stress was observed in those who kept doing PA during COVID-19 outbreak. People who stopped physical activity or started activity during the pandemic did not show the same benefits of the practice in the PS. Sleep changes and BMI were positively associated with PS. Despite the present findings in this sample, the elderly's stress levels were generally low, demonstrating that the elderly may to have greater stress management capacity during the COVID-19 outbreak.

\section{Conflict of interest}

The authors declare no conflict of interest.

\section{Funding}

This work was financial supported by the Fundação de Amparo à Pesquisa do Amazonas (FAPEAM) and Coordenação de Aperfeiçoamento de Pessoal de Nível Superior (CAPES).

\section{Author's contributions}

Alcântara CH, Leon EB and Costa RM were responsible for study conceptualization, data collection, data analysis, and drafting of the manuscript. Brito $\mathrm{E}$ and Marques MMS contributed for conceptualization, methodology, investigation and data collection. Ribeiro EE are responsible for conceptualization, supervision, project administration and funding acquisition. All authors read and reviewed the manuscript before approving it for submission.

\section{Acknowledgments}

The authors would like to thank the professionals at Policlínica Gerontológica da FUnATI, the research team and the patients.

\section{References}

1. Zhu N, Zhang D, Wang W, Li X, Yang B, Song J, et al. A Novel Coronavirus from Patients with Pneumonia in China, 2019. N Engl J Med [Internet]. 2020 Feb 20;382(8):72733. Available from: http://www.nejm.org/doi/10.1056/ NEJMoa2001017

2. Wu JT, Leung K, Leung GM. Nowcasting and forecasting the potential domestic and international spread of the 2019$\mathrm{nCoV}$ outbreak originating in Wuhan, China: a modelling study. Lancet [Internet]. 2020 Feb 29;395(10225):68997. Available from: https://doi.org/10.1016/S01406736(20)30260-9

3. World Health Organization. Global influenza strategy 2019-2030 [Internet]. Geneva PP - Geneva: World Health Organization; 2019. Available from: https://apps.who.int/ iris/handle/10665/311184
4. Pfefferbaum B, North CS. Mental Health and the Covid-19 Pandemic. N Engl J Med [Internet]. 2020 Aug 6 [cited 2020 Oct 27];383(6):510-2. Available from: https://www.nejm. org/doi/10.1056/NEJMp2008017

5. García-Fernández L, Romero-Ferreiro V, López-Roldán PD, Padilla S, Rodriguez-Jimenez R. Mental Health in Elderly Spanish People in Times of COVID-19 Outbreak. Am J Geriatr Psychiatry. 2020; (January).

6. Huang Y, Zhao N. Generalized anxiety disorder, depressive symptoms and sleep quality during COVID-19 outbreak in China: a web-based cross-sectional survey. Psychiatry Res [Internet]. 2020;288(March):112954. Available from: https://doi.org/10.1016/j.psychres.2020.112954

7. Monteiro-Junior RS, Carneiro LSF, Barca ML, Kristiansen KM, Sampaio CA, Haikal DS, et al. COVID-19 pandemic: a multinational report providing professional experiences in the management of mental health of el-derly. Int Psychogeriatrics [Internet]. 2020 May 29 [cited 2020 Jul 24];1-4. Available from: https://doi.org/10.1017/S1041610220001027

8. Nigdelis MP, Martínez-Domínguez SJ, Goulis DG, Pérez-López FR. Effect of programmed exercise on perceived stress in middle-aged and old women: A metaanalysis of randomized trials. Maturitas [Internet]. 2018 Aug;114(April):1-8. Available from: https://doi. org/10.1016/j.maturitas.2018.05.004

9. Albert MA, Durazo EM, Slopen N, Zaslavsky AM, Buring JE, Silva T, et al. Cumulative psychological stress and cardiovascular disease risk in middle aged and older women: Rationale, design, and baseline characteris-tics. Am Heart J [Internet]. 2017;192:1-12. Available from: http://www. sciencedirect.com/science/article/pii/S0002870317301850

10. Cohen S, Janicki-Deverts D. Who's Stressed? Distributions of Psychological Stress in the United States in Probability Samples from 1983, 2006, and 2009. J Appl Soc Psychol. 2012;42(6):1320-34.

11. Osmanovic-Thunström A, Mossello E, Åkerstedt $\mathrm{T}$, Fratiglioni L, Wang HX. Do levels of perceived stress increase with increasing age after age 65 ? A population-based study. Age Ageing. 2015;44(5):828-34.

12. Liu Y, Li T, Guo L, Zhang R, Feng X, Liu K. The mediating role of sleep quality on the relationship between perceived stress and depression among the elderly in urban communities: a cross-sectional study. Public Health [Internet]. 2017 Aug 1 [cited 2020 Jul 28];149:21-7. Available from: https:// linkinghub.elsevier.com/retrieve/pii/S0033350617301439

13. Guérin E, Biagé A, Goldfield G, Prud'homme D. Physical activity and perceptions of stress during the meno-pause transition: A longitudinal study. J Health Psychol [Internet]. 2019 May 5;24(6):799-811. Available from: http://journals. sagepub.com/doi/10.1177/1359105316683787

14. Wang Y, Di Y, Ye J, Wei W. Study on the public psychological states and its related factors during the out-break of coronavirus disease 2019 (COVID-19) in some regions of China. Psychol Heal Med. 2020;8506.

15. Charles ST, Luong G, Almeida DM, Ryff C, Sturm M, Love G. Fewer Ups and Downs: Daily Stressors Me-diate Age Differences in Negative Affect. Journals Gerontol Ser B [Internet]. 2010 May 1;65B(3):279-86. Available from: https://doi.org/10.1093/geronb/gbq002

16. Mroczek DK, Almeida DM. The Effect of Daily Stress, Personality, and Age on Daily Negative Affect. J Pers [Internet].2004 Apr 1;72(2):355-78. Available from: https:// doi.org/10.1111/j.0022-3506.2004.00265.x 
17. de Moraes EN, do Carmo JA, de Moraes FL, Azevedo RS, Machado CJ, Montilla DER. Clinical-Functional Vulnerability Index-20 (IVCF-20): Rapid recognition of frail older adults. Rev Saude Publica [Internet]. 2016 Dec 22 [cited 2020 Jul 21];50:81. Available from: http://www.rsp. fsp.usp.br/2

18. Franco MR, Tong A, Howard $K$, Sherrington C, Ferreira $P H$, Pinto RZ, et al. Older people's perspectives on participation in physical activity: a systematic review and thematic synthesis of qualitative literature. Br J Sports Med [Internet]. 2015 Oct;49(19):1268-76. Available from: http://bjsm.bmj. com/lookup/doi/10.1136/bjsports-2014-094015

19. Matias TS, Dominski FH. The COVID-19 pandemic challenges physical activity with two emerging para-digms. Rev Bras Atividade Física Saúde [Internet]. 2020;25(SESéries Técnicas em Atividade Física e Saúde):1-6. Available from: https://rbafs.org.br/RBAFS/article/view/14233

20. Paolucci EM, Loukov D, Bowdish DME, Heisz JJ. Exercise reduces depression and inflammation but intensi-ty matters. Biol Psychol [Internet]. 2018;133:79-84. Available from: http://dx.doi.org/10.1016/j.biopsycho.2018.01.015

21. Pauly T, Michalowski VI, Nater UM, Gerstorf D, Ashe MC, Madden KM, et al. Everyday associations be-tween older adults' physical activity, negative affect, and cortisol. Heal Psychol. 2019;38(6):494-501.

22. Mücke M, Ludyga S, Colledge F, Gerber M. Influence of Regular Physical Activity and Fitness on Stress Re-activity as Measured with the Trier Social Stress Test Protocol: A Systematic Review. Sport Med [Internet].2018;48(11):260722. Available from: https://doi.org/10.1007/s40279-0180979-0

23. Klaiber P, Wen JH, DeLongis A, Sin NL. The ups and downs of daily life during COVID-19: Age differences in affect, stress, and positive events. Journals Gerontol Ser B [Internet]. 2020 Jul 17;(2):1-27. Available from: https://academic.oup. com/psychsocgerontology/advance-article/doi/10.1093/ geronb/gbaa096/5872612
24. Moraes W, Piovezan R, Poyares D, Bittencourt LR, Santos-Silva R, Tufik S. Effects of aging on sleep struc-ture throughout adulthood: A population-based study. Sleep Med [Internet]. 2014;15(4):401-9. Available from: http://dx.doi. org/10.1016/j.sleep.2013.11.791

25. Marengoni A, Angleman S, Melis R, Mangialasche F, Karp A, Garmen A, et al. Aging with multimorbidity: A systematic review of the literature. Ageing Res Rev [Internet]. 2011 Sep 1 [cited 2020 Aug 5];10(4):430-9. Available from: https:// linkinghub.elsevier.com/retrieve/pii/S1568163711000249

26. Fortin M, Bravo G, Hudon C, Lapointe L, Dubois M-F, Almirall J. Psychological Distress and Multimorbidi-ty in Primary Care. Ann Fam Med [Internet]. 2006 Sep 1 [cited 2020 Aug 5];4(5):417-22. Available from: https://www. annfammed.org/content/4/5/417

27. Pulopulos MM, Hidalgo V, Almela M, Puig-Perez S, Villada C, Salvador A. Hair cortisol and cognitive per-formance in healthy older people. Psychoneuroendocrinology [Internet]. 2014;44:100-11. Available from: http://dx.doi.org/10.1016/j. psyneuen.2014.03.002

28. Pulopulos MM, Puig-Perez S, Hidalgo V, Montoliu T, Salvador A. Acute Cortisol Levels and Memory Performance in Older People with High and Normal Body Mass Index. Span J Psychol. 2019;1-18.

29. Hamer M, Poole L, Messerli-Bürgy N. Television viewing, $\mathrm{C}$-reactive protein, and depressive symptoms in older adults. Brain Behav Immun. 2013;33:29-32.

30. Endrighi R, Steptoe A, Hamer M. The effect of experimentally induced sedentariness on mood and psychobio-logical responses to mental stress. Br J Psychiatry. 2016;208(3):245-51.

Received: 25/05/2021

Approved: 01/10/2021

Quote this article as:

Alcântara CH, Leon EB, Costa RM, Brito E, Marques MMS, Ribeiro EE. Physical activity is associated with low-level stress among a sample of seniors during COVID-19 outbreak? Rev Bras Ativ Fís Saúde. 2021;26:e0226. DOI: 10.12820/rbafs.26e0226 